
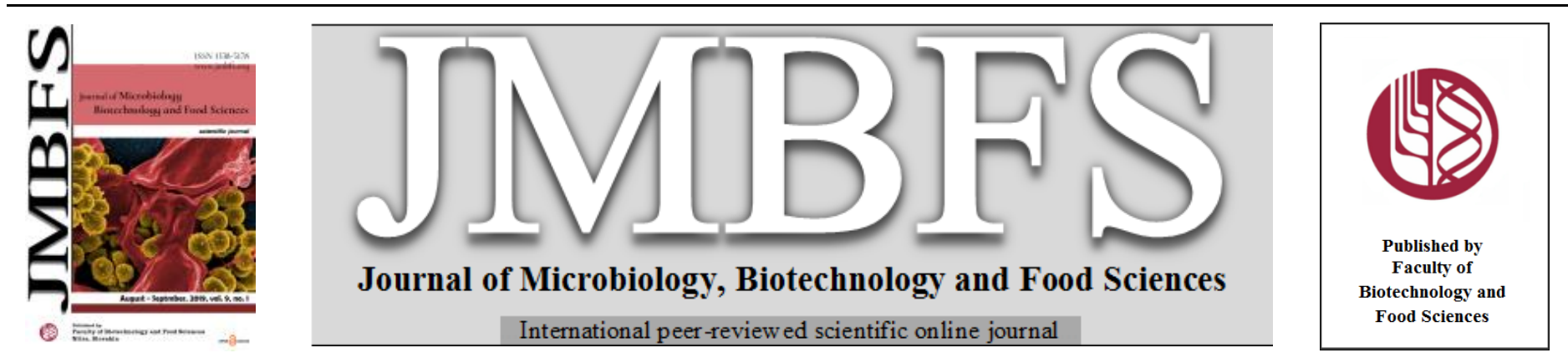

\title{
EVALUATION OF THE ANTIMICROBIAL PROPERTIES OF EEL SKIN MUCUS FROM MONOPTERUS ALBUS AGAINST SELECTED ORAL PATHOGENS AND IDENTIFICATION OF THE ANTI-ORAL BIOACTIVE COMPOUNDS USING LC-QTOF-MS
}

\author{
Ayah Rebhi Hilles ${ }^{1 *}$, Syed Mahmood ${ }^{2,3 *}$, Mohd Arifin Kaderi $^{l}$, Ridzwan Hashim $^{l}$ \\ $\operatorname{Address}(e s)$ : \\ ${ }^{1}$ Department of Biomedical Sciences, Kulliyyah of Allied Health Sciences, International Islamic University Malaysia, 25200 Kuantan, Pahang, Malaysia. \\ ${ }^{2}$ Department of Pharmaceutical Engineering, Faculty of Engineering Technology, University Malaysia Pahang, 26300 Gambang, Pahang, Malaysia. \\ ${ }^{3}$ Centre of Excellence for Advanced Research in Fluid Flow (CARIFF), University Malaysia Pahang, 26300 Gambang, Pahang, Malaysia.
}

*Corresponding author: syedmahmood@ump.edu.my, ayah.hilles90@gmail.com

doi: 10.15414/jmbfs.2019.9.1.140-143

\section{ARTICLE INFO}

Received 19. 10. 2018

Revised 8. 6. 2019

Accepted 10. 6. 2019

Published 1. 8. 2019

Regular article OPEN $\partial_{\text {ACCESS }}$

\begin{abstract}
Despite great achievements in the oral health of populations globally, oral health problems remain in many communities all over the world, thus our study aimed to evaluate the antimicrobial activity of Monopterus albus skin mucus against selected oral pathogens. Monopterus albus is Asian swamp eel with elongated body like snakes. Their skin covered with a thick layer of mucus. They are usually found as a sluggish in the stagnant waters as it has a weak swimming behavior. Although eels are capable of quick movements, but they tend to be lethargic and they rely on stealth swimming movements to capture their prey such as shrimp, frogs and other small fishes. With regard to this matter, aqueous and methanol extracts were prepared to test antimicrobial activities against selected oral pathogens; Gram-positive bacteria i.e. Enterococcus faecalis, Streptococcus pyogenes, Streptococcus mutans, Gram-negative bacteria which are Klebsiella pneumoniae, Pseudomona aeruginosa and fungus pathogens i.e. Candida albicans. The antimicrobial activities were determined by inhibition percentage. The results showed a dramatic decrease in the oral pathogens treated with eel skin mucus methanol extract higher than the aqueous extract. Enterococcus faecalis showed the highest activity while Candida albicans showed the lowest activity. After in-vitro evaluation for eel skin mucus activities, identification study using liquid chromatography-quadrupole-time-offlight mass spectrometry (LC-QTOF-MS) was performed to investigate the compound responsible for the anti-oral pathogens activities, the results showed the presence of salvianolic acid $\mathrm{G}$ which strongly corelated with the antimicrobial activity against selected oral pathogens. Results were statistically significant with $p<0.001$. In conclusion, the present study revealed that eel skin mucus can be considered as promising source for anti-oral pathogens activities.
\end{abstract}

Keywords: Monopterus albus, oral pathogens, liquid chromatography-quadrupole-time-of-flight mass spectrometry, salvianolic acid G

\section{INTRODUCTION}

Asian swamp eel, Monopterus albus (M. albus) belongs to synbranchidae family under the order of synbranchiformes (Rossen, \& Greenwood, 1976). It is native to the tropical and subtropical areas of northern India, China, Malaysia, Thailand, Indonesia, Philippines and possibly North-Eastern Australia (Collins et al., 2002). It has elongated shape of the body which covered by a thick protective mucous layer (Liem, 1967).

Oral diseases remain a major public health problem worldwide as the oral cavity exposed to many pathogens. A global review on oral health that has been published by WHO emphasized that oral health is still considered as a global problem even though some countries have achieved great improvements in the oral health management (Petersen, 2003).

Enterococcus faecalis is known to be the most frequent species in root canals with failed endodontic therapy (Wang et al., 2011). Streptococcus pyogenes can cause a systemic infection through oral infection (Inagaki et al., 2017). Streptococcus mutans is a major risk cause for childhood and future dental caries (Berkowitz, 2003). Lung destruction caused by the chronic colonization of Pseudomonas aeruginosa (Caldas et al., 2015). Oral candidiasis is the most common fungal infection (Abu-Elteen \& Abu-Alteen, 1998) which caused by overgrowth of Candida species in the oral cavity (Akpan \& Morgan, 2002)

Liquid chromatography quadrupole time-of-flight mass spectrometry performed very well, with high sensitivities and specificities reach up to $95 \%$. It is a powerful analytical method which has high-resolution mass (Kronstrand et al., 2014). The importance of liquid chromatography-quadrupole-time-of-flight mass spectrometry (LC-QTOF-MS) has appeared as a useful technique for identification of the compounds (Kosjek \& Heath, 2008), due to the special combination of high selectivity and structural information originated from accurate-mass MS and MS/MS spectra (Gómez et al., 2010). Thereby, the potential of LC-QTOF-MS evaluated both quantitative and qualitative abilities (González-Mariño et al., 2011).

\section{MATERIALS AND METHODS}

\section{Preparation of eel skin mucus (ESM) extract}

Healthy Asian swamp eels (Monopterus albus) were collected from eel farm in Pekan, Pahang, Malaysia. Eel skin mucus was homogenized with 2 volumes of distilled water, then centrifuged at $13,000 \mathrm{rpm}$ for $30 \mathrm{~min}$, the supernatant lyophilized. Dried substance weighed and dissolved in distilled water to form aqueous extract and in methanol to form organic extract, after that, the dissolved substance filtered using a syringe filter and kept until use (Sadakane et al., 2007).

\section{Determination of antimicrobial activities}

\section{Microbial strains}

The microorganisms used in this study; Gram-positive bacteria which are; Enterococcus faecalis (ATCC 29212), Streptococcus pyogenes (ATCC 19615), Streptococcus mutans (ATCC 25175), Gram-negative bacteria which are Klebsiella pneumoniae (ATCC 700603), Pseudomona aeruginosa (ATCC 27853) and fungi which is Candida albicans (ATCC MYA 4901) as oral pathogens. All strains have been procured from the American Type Culture Collection (ATCC, Manassas, VA, USA). 


\section{Preparation of Inoculums}

All the oral bacterial strains were incubated at $37{ }^{\circ} \mathrm{C}$ for $18-24 \mathrm{hrs}$ whereas 24 hrs at $30{ }^{\circ} \mathrm{C}$ for fungi. The turbidity of the suspensions adjusted according to McFarland standard (approximately $5 \times 10^{8} \mathrm{CFU} / \mathrm{mL}$ ) which represent the absorbance of $0.08-0.10$ at $625 \mathrm{~nm}$ for bacteria, while for fungi, the suspension was adjusted at $600 \mathrm{~nm}$ to match the turbidity of 0.5 of McFarland standard (0.5$\left.2.5 \times 10^{5} \mathrm{CFU} / \mathrm{mL}\right)($ Leite et al., 2014)

Determination of anti-oral pathogens activities by growth of inhibition method and $\mathrm{IC}_{50}$ determination

The growth of inhibition method was conducted using sterile 96-well plate, all wells were filled with $100 \mu \mathrm{L}$ of Mueller-Hinton agar. Then $100 \mu \mathrm{L}$ volume of serial dilution from the extracts were added from the concertation 1000 to 7.81 $\mu \mathrm{g} / \mathrm{mL}$. After this $50 \mu \mathrm{l}$ of adjusted inoculum was seeded into each well. The plates were incubated at $37^{\circ} \mathrm{C}$ for $24 \mathrm{hrs}$. The turbidity of the medium was measured by ELISA microplate reader at $630 \mathrm{~nm}$. The percentage of inhibition calculated from the formula: 1- (Absorbance of test well/Absorbance of corresponding control well) $\times 100$ (Patton et al., 2006). $\mathrm{IC}_{50}$ values were calculated by determining the concentration required for $50 \%$ inhibition of bacterial growth after adding the extracts (Miyoshi et al., 2003).

Identification the bioactive compounds against oral pathogens using LCQTOF-MS

The solvents used for the mobile phase were as follows: solvent name A (water $+0.1 \%$ Formic Acid), solvent B: (acetonitrile) for LC-MS in gradient grade solvents as shown in table 1 and ammonium acetate was used for HPLC grade Column: C-18. All measurements were performed with a Q-TOF LC-MS instrument (Waters VION Ion Mobility QTOF MS). The QTOF-MS was operated with an electrospray positive and negative ionization mode, mass resolution of (100-1000) $\mathrm{m} / \mathrm{z}$ measure the frequency of 10,000 transients $\mathrm{s}^{-1}$, the low collision energy was $4.00 \mathrm{eV}$ while the high collision energy ramp started with $10.00 \mathrm{eV}$ and ended with $45.00 \mathrm{eV}$.

Table 1 The Gradient grade of solvents in the mobile phase.

\begin{tabular}{lllll}
\hline Time $(\mathrm{min})$ & $\begin{array}{l}\text { Flow Rate } \\
(\mathrm{mL} / \mathrm{min})\end{array}$ & Solvent A (\%) & Solvent B (\%) & curve \\
\hline 0.00 & 0.600 & 99.0 & 1.0 & Initial \\
0.50 & 0.600 & 99.0 & 1.0 & 6 \\
10.00 & 0.600 & 65.0 & 35.0 & 6 \\
13.00 & 0.600 & 0.0 & 100.0 & 1 \\
15.00 & 0.600 & 99.0 & 1.0 & 1 \\
\hline
\end{tabular}

\section{RESULTS}

Percentage of inhibition and $\mathrm{IC}_{50}$

The results in figure 1 showed that methanol eel skin mucus extract has higher antimicrobial activities than the aqueous extract, the highest inhibition activity of methanol extract was against Enterococcus faecalis which was $81.74 \pm 0.43 \%$ and $50.74 \pm 0.19 \%$ at the concentration of $1000 \mu \mathrm{g} / \mathrm{mL}$ and $7.81 \mu \mathrm{g} / \mathrm{mL}$ respectively. The extracts were exhibited inhibition activity against Streptococcus mutans with $78.13 \pm 0.61 \%$ and $44.30 \pm 0.44 \%$ at $1000 \mu \mathrm{g} / \mathrm{mL}$ of methanol and aqueous extracts respectively. Whereas the percentage of inhibition against Streptococcus pyogenes was $76.01 \pm 0.23 \%$ in the methanol extract and $68.24 \pm 0$ $.77 \%$ and in the aqueous extract at $1000 \mu \mathrm{g} / \mathrm{mL}$ respectively. Klebsiella pneumoniae was inhibited with $72.84 \pm 0.11 \%$ in the methanol extract and 68.21 $\pm 0.34 \%$ in the aqueous extract at $1000 \mu \mathrm{g} / \mathrm{mL}$. Pseudomonas aeruginosa was inhibited in the methanol extract with $69.5 \pm 0.79 \%$ while $51.44 \pm 0.61 \%$ in the aqueous extract at $1000 \mu \mathrm{g} / \mathrm{mL}$ respectively. The lowest inhibition was against Candida albicans which was $59.37 \pm 0.42 \%$ in the methanol extract and $50.78 \pm$ $0.18 \%$ in the aqueous extract at $1000 \mu \mathrm{g} / \mathrm{mL}$. The results showed variation in the $\mathrm{IC}_{50}$ in different extracts and different pathogens as shown in table 2.

Table 2 Determination of $\mathrm{IC}_{50}(50 \%$ inhibition concentration) of ESM extracts.

\begin{tabular}{lll}
\hline Oral pathogen & Methanol extract & Aqueous extract \\
\hline Enterococcus faecalis & $7.15 \pm 0.73^{* *}$ & $15.93 \pm 0.52^{* *}$ \\
Streptococcus mutans & $12.89 \pm 0.15^{* *}$ & $54.68 \pm 0.81^{* *}$ \\
Streptococcus pyogenes & $9.75 \pm 0.91^{* *}$ & $97.21 \pm 0.74 * *$ \\
Klebsiella pneumoniae & $13.56 \pm 0.28^{* *}$ & $124.82 \pm 0.01 * *$ \\
Pseudomona aeruginosa & $23.44 \pm 0.43^{* *}$ & $187.47 \pm 0.6 * *$ \\
Candida albicans & $379.91 \pm 0.5^{* *}$ & $761.38 \pm 0.29 *$ \\
\hline
\end{tabular}

Data expressed in $\mu \mathrm{g} / \mathrm{mL}$, mean $\pm \mathrm{SD}(\mathrm{n}=3)$. ** Significant difference at $p<$ 0.001 (one-way ANOVA.
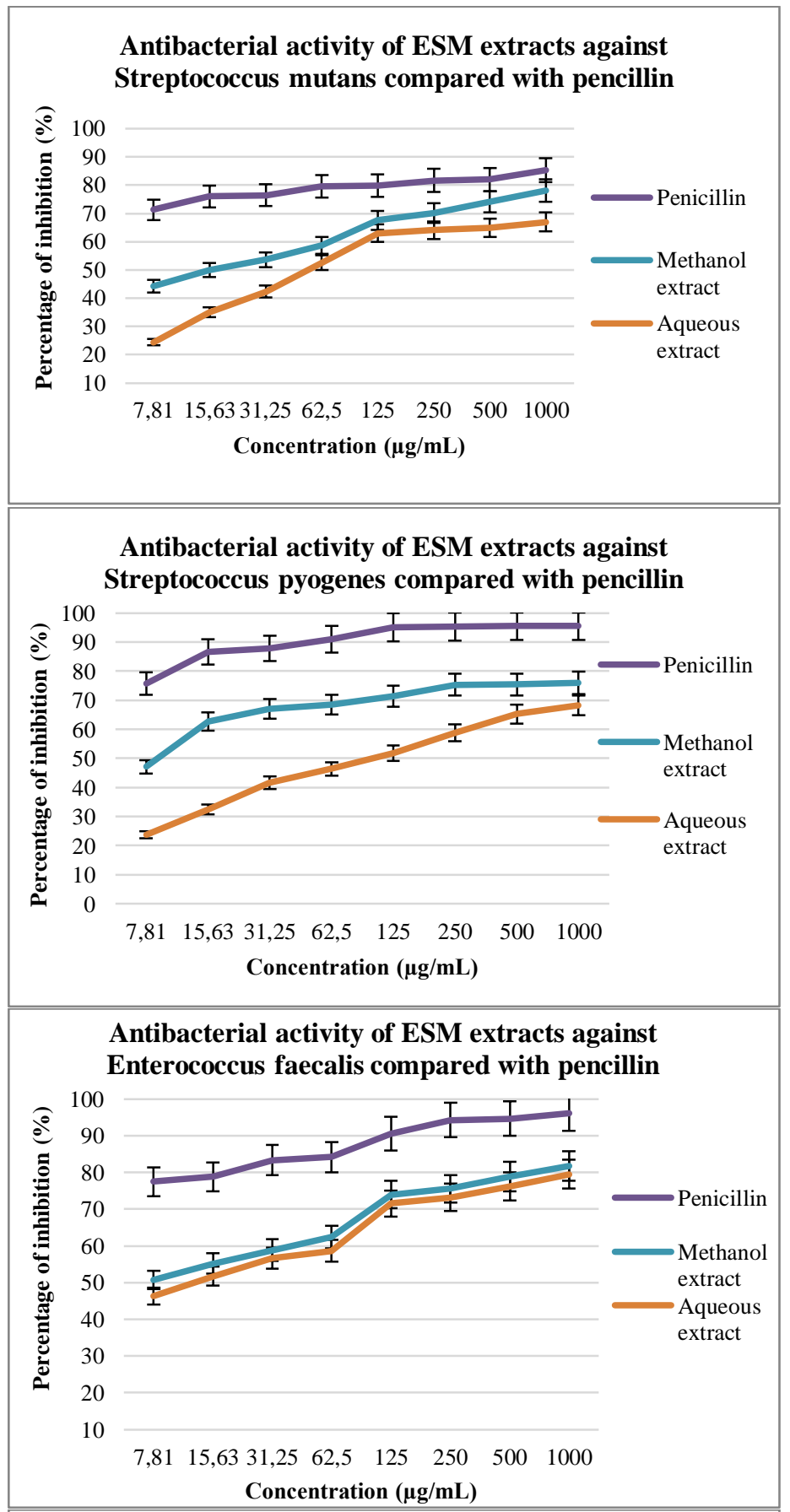

Antibacterial activity of ESM extracts against Pseudomona aeruginosa compared with pencillin

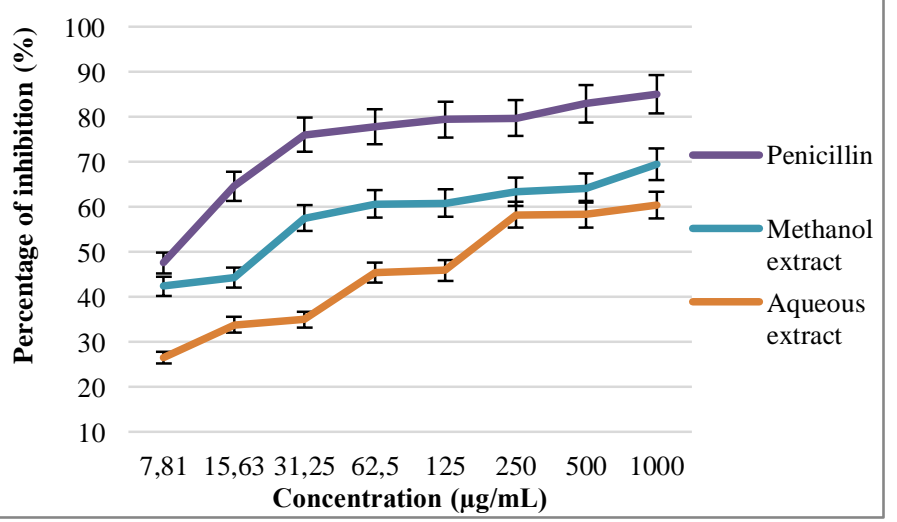



Antibacterial activity of ESM extracts against
Klebsiella pneumoniae compared with pencillin
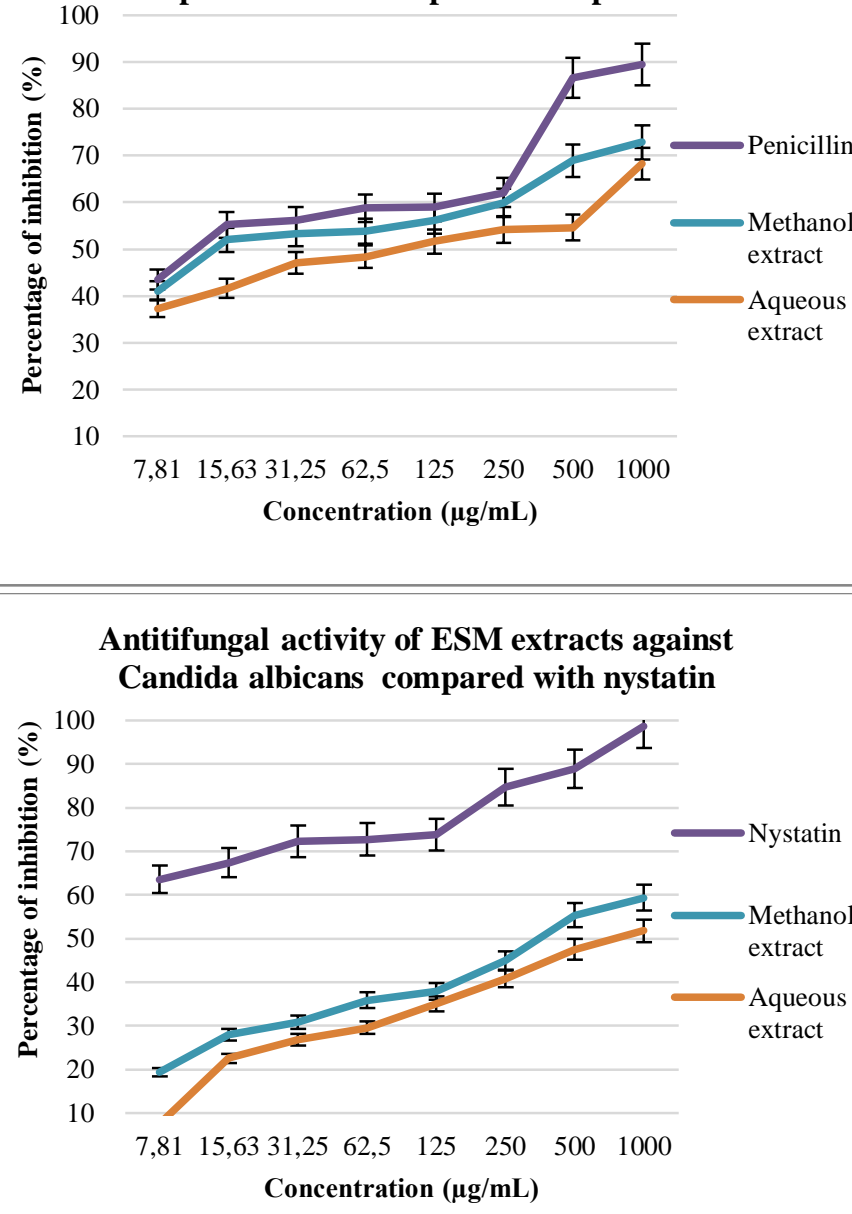

Figure 1 Percentage of inhibition antimicrobial activities of eel skin mucus aqueous and methanol extracts against selected oral pathogens compared with positive control. Data were expressed mean. Data presented as means $\pm \mathrm{SD}$ $(n=3)$

\section{Compound identification using LC-QTOF-MS}

LC-QTOF-MS data showed the presence of salvianolic acid G (figure 2), which identified and characterised as shown in table 2 . It has been invented that salvianolic acid effective to kill viruses and bacteria in the mouth to prevent dental caries and periodontitis, and the treatment of other oral and throat diseases (Chinese Patent number CN 102743436 A).

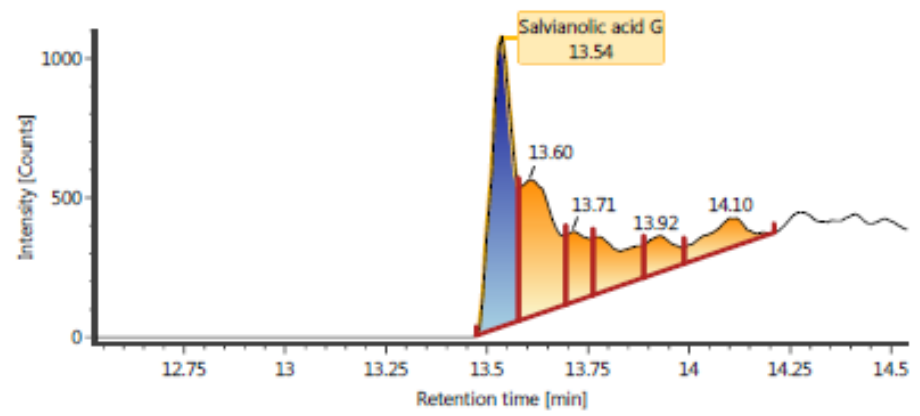

González-Mariño, I., Quintana, J. B., Rodríguez, I., \& Cela, R. (2011) Evaluation of the occurrence and biodegradation of parabens and halogenated byproducts in wastewater by accurate-mass liquid chromatography-quadrupoletime-of-flight-mass spectrometry (LC-QTOF-MS). Water research, 45(20), 6770-6780. https://doi.org/10.1016/j.watres.2011.10.027

Inagaki, Y., Abe, M., Inaki, R., Zong, L., Suenaga, H., Abe, T., \& Hoshi, K. (2017). A Case of Systemic Infection Caused by Streptococcus pyogenes Oral Infection in an Edentulous Patient. Diseases, 5(3) 17. https://doi.org/10.3390/diseases5030017

Kosjek, T., \& Heath, E. (2008). Applications of mass spectrometry to identifying pharmaceutical transformation products in water treatment. TrAC Trends in Analytical Chemistry, 27(10), 807-820. https://doi.org/10.1016/j.trac.2008.08.014 
Kronstrand, R., Brinkhagen, L., Birath-Karlsson, C., Roman, M., \& Josefsson, M. (2014). LC-QTOF-MS as a superior strategy to immunoassay for the comprehensive analysis of synthetic cannabinoids in urine. Analytical and bioanalytical chemistry, 406(15), 3599-3609. https://doi.org/10.1007/s00216013-7574-X.

Leite, V. M. F., Pinheiro, J. B., Pisani, M. X., Watanabe, E., Souza, R. F. D., Paranhos, H. D. F. O., \& Lovato-Silva, C. H. (2014). In vitro antimicrobial activity of an experimental dentifrice based on Ricinus communis. Brazilian dental journal, 25(3), 191-196. http://dx.doi.org/10.1590/0103-6440201302382

Liem, K. F. (1967). Functional morphology of the integumentary, respiratory, and digestive systems of the synbranchoid fish Monopterus albus. Copeia, 375388.

Miyoshi, N., Kawano, T., Tanaka, M., Kadono, T., Kosaka, T., Kunimoto, M., ... \& Hosoya, H. (2003). Use of Paramecium species in bioassays for environmental risk management: determination of IC50 values for water pollutants. Journal of health science, 49(6), 429-435. https://doi.org/10.1248/jhs.49.429.

Patton, T., Barrett, J., Brennan, J., \& Moran, N. (2006). Use of a spectrophotometric bioassay for determination of microbial sensitivity to manuka honey. Journal of Microbiological Methods,64(1), 84-95. https://doi.org/10.1016/j.mimet.2005.04.007

Petersen, P. (2003). The World Oral Health Report 2003: continuous improvement of oral health in the 21 st century - the approach of the WHO Global Oral Health Programme. Community Dent Oral Epidemiol. Dec;31 Suppl 1:3 -24. https://doi.org/10.1046/j..2003.com122.x

Rossen, D. E. \& Greenwood, P. H. (1976). A fourth neotropical species of Synbranchid eel and the phylogeny and systematics of Synbranchiform fishes. Bulletin of American Museum of Natural History, 157, 1-69.

Sadakane, Y., Konoha, K., Nagata, T., \& Kawahara, M. (2007). Protective activity of the extracts from Japanese eel (Anguilla japonica) against zincinduced neuronal cell death: Carnosine and an unknown substance. Trace Nutr. Res, 24, 98-105.

Wang, L., Dong, M., Zheng, J., Song, Q., Yin, W., Li, J., \& Niu, W. (2011). Relationship of biofilm formation and gelE gene expression in Enterococcus faecalis recovered from root canals in patients requiring endodontic retreatment. Journal of endodontics, 37(5), 631-636. https://doi.org/10.1016/j.joen.2011.02.006 